\title{
ХАРАКТЕРИСТИКА ПРОЦЕССОВ И СТАДИЙ ТЕАТРАЛЬНОГО ПРОЕКТА
}

Бирюкова Нина Алексеевна

Государственный Академический Большой театр России, г. Москва

Аннотация: Сравнение традиционного и проектно-ориентированного подхода в управлении театральной организацией. Определение этапов создания театрального проекта. Определение ролей участников проекта. Экономическая оценка проекта.

Ключевые слова: Театр, театральный проект, продюсер, проектноориентированный подход, управление театральным проектом.

\section{CHARACTERISTICS OF THE PROCESSES AND STAGES OF A THEATRICAL PROJECT}

\section{Biriukova Nina}

Abstract: Comparison of the traditional and project-oriented approaches to managing a theater organization. Determining the stages of creating a theatrical project. Defining the roles of the project participants. Economic evaluation of the project.

Key words: Theater, theater project, producer, project-oriented approach, theater project management.

Возрастающая конкуренция в сфере культуры и в частности, в сфере театральной деятельности создает необходимость поиска инновационных подходов в управлении. Одним из таких подходов является проектноориентированная деятельность. Применение проектного-ориентированного подхода формирует условия для привлечения дополнительного финансирования в культурную и театральную сферу: частных и государственных инвестиций, а также формирует предпосылки для экономической стабильности. Внедрение новшества, создание уникального по 


\section{СОВРЕМЕННЫЕ СОЦИАЛЬНО-ЭКОНОМИЧЕСКИЕ ПРОЦЕССЫ: ПРОБЛЕМЫ, ТЕНДЕНЦИИ, ПЕРСПЕКТИВЫ}

своим характеристикам творческого продукта - является главным результатом проектной деятельности.

Во вторую очередь театральный проект важно изучать как форму организации театральной деятельности, в ходе которой, в условиях ограниченных временных, финансовых и трудовых ресурсах, реализуется креативная творческая идея автора проекта - продюсера.

Исследование сущности театрального проекта и поиск эффективных подходов к его реализации является актуальной темой для изучения многими специалистами. Это подтверждает значительное количество книг, учебников, статей и иных публикаций в данной области. Особенно значимый вклад в исследование процесса создания театрального проекта внесли труды Д.Я. Смелянского, Г.Г. Дадамяна, Д.Г. Стрельцова, Д.Г.Самитов, Г.А. Заславского, в которых дается характеристика профессии продюсера и раскрываются основные аспекты его деятельности. Тему финансирования театральных проектов подробно раскрываются работы таких ученых как А.Е. Князева, В.Ю. Музычук, А.А. Клецина. Актуальные направления развития театральных проектов отражают работы Ф. Елютина, В.Ю. Гацук-Шерпиловой, Т.В. Портновой.

Наличие элементов проектного-ориентированного подхода в практике театральной организации при создании спектакля, подготовке гастролей, организации фестивалей, подтверждается тем, что данную работу можно представить как уникальный процесс, в контексте которого осуществляется управление действиями, ориентированными на достижение результатов, в условиях ограниченных временных, пространственных и финансовых pecypcax.

Традиционный подход в системе управления репертуарным театром представляет собой программный подход. Репертуар в данном случаем представлен как «комплекс взаимосвязанных проектов и мероприятий, объединенных общей целью и координируемых совместно в целях повышения общей результативности и управляемости» ${ }^{1}$. Таким образом, можно сделать вывод, что управление репертуарной политикой в театре схоже с методом управления портфелем проектов.

В реальности, проектное управление в сфере театральных организаций в основном имело стихийный характер, отсутствие цельной системы в организации проектной деятельности приводило к нарушению 
координированных действий, а так же необходимого взаимодействия между проектом и системой его финансового обеспечения, налоговыми обязательствами, что несомненно снижает эффективность проектного управления.

Характеристика театрального проекта.

Проект-спектакль обладает следующими характеристиками:

- Уникальностью

- Невещественностью

- Состоит из процесса создания и проката спектакля и соответствующих действий данным процессам

- Наличие рисков и неопределенности

- Ориентацией на зрительское признание и положительную оценку со стороны критики

- Ограниченностью в финансовых и временных ресурсах

- Наличие определенных участников команды, подобранных относительно требований режиссера, продюсера и руководителя

- Готовность к определенным изменениям в ходе проката постановки, которые согласованы заранее в контракте

Распределение ролей, среди участников проекта.

Перечисленные выше свойства проекта-спектакля входят в зону ответственности продюсера, инициатора проекта. Художественный руководитель спектакля несет ответственность за художественно-творческий аспект проекта, конкретно за предмет деятельности проекта. Формирование обеспечения ресурсами необходимыми для реализации проекта занимается директор проекта. Задачи других участников проекта распределяет художественный руководитель, среди них участники непосредственного художественно-постановочного процесса. Обеспечение проекта услугами, контроль и разработка задач относится к сфере деятельности помощников продюсера и работников административно-хозяйственной части.

Процессы и стадии театрального проекта-спектакля.

Уникальной особенностью театрального проекта является формирование двух различных по форме и содержанию процессов: художественно-постановочного процесса и процесса реализации созданного спектакля. 


\section{СОВРЕМЕННЫЕ СОЦИАЛЬНО-ЭКОНОМИЧЕСКИЕ ПРОЦЕССЫ: ПРОБЛЕМЫ, ТЕНДЕНЦИИ, ПЕРСПЕКТИВЫ}

Каждый творческий проект основывается на определенной идее или замысле, которыми могут обладать как продюсер или режиссер, так и композитор или художник. Далее в процесс включаются другие участники проекта, идея формирует цели проекта, планы и задачи. Затем начинается процесс непосредственной материализации идеи, средствами искусства, а именно осуществление замысла, посредством создания на сцене театральной постановки.

Давая экономическую оценку театральному проекту, важно отметить, что организации процесса воплощения замысла, предшествует поиск необходимых ресурсов, а именно финансовых по средством привлечения различных источников финансирования. Данное обязательство ставит перед собой продюсер проекта. Таким образом, художественно-постановочный процесс театрального проекта, логично определить как затратный период, так как на данном периоде необходимо привлечь большой объем финансовых средств. Объем привлеченных ресурсов определяет необходимость в первичном капитале, вкладываемом в реализацию проекта.

Обобщая научные положения А.Шторха, изложенные им в труде «Курс политической экономики, или Изложение начал, обуславливающих народное благоденствие. Размышление о природе национального дохода», можно сделать вывод, что высокий уровень национального богатства, является определенной основой для источников финансирования культуры, будь то частные или государственные формы, благосостояние которых в свою очередь влияет на полноценность материально-финансового обеспечения деятельности конкретных культурных организаций.

Формирование качества не овеществленного продукта, которое в дальнейшем определит его инновационность и уникальность происходит в период постановки спектакля. На данной стадии так же формируются предпосылки убыточности проекта театральной деятельности.

Обобщая вышесказанное, можно сделать вывод что на первоначальной стадии проекта - постановочного процесса, дается экономическая характеристика проекта и выявляются качественные свойства реализуемого художественного замысла, в аспекте материально-финансового обеспечения. Исходя из этого следует рассмотреть следом идущую стадию- прокат спектакля проекта. 


\section{СОВРЕМЕННЫЕ СОЦИАЛЬНО-ЭКОНОМИЧЕСКИЕ ПРОЦЕССЫ: ПРОБЛЕМЫ, ТЕНДЕНЦИИ, ПЕРСПЕКТИВЫ}

Принятый к прокату спектакль обретает черты уже не только воплощенного художественного образа, но и продукта, созданного для удовлетворения культурных потребностей граждан (конкретно зрительской аудитории).

На данной стадии первоначальная идея проекта трансформируется из задуманной в реализованную. Реализация идеи подразумевает достижение творческим продуктом определенных целей, a именно: обретает востребованность, среди целевой аудитории, тех кто испытывает потребность в получении данного продукта; становится полезным для потребителязрителя, который находится в поиске художественных смыслов и ценностей; обретает собственную стоимость и цену, то есть становится «ценным».

Однако, стоит отметить, что процесс потребления театрального продукта неоднозначен.

В первую очередь в связи с тем, что театральная постановка обладает определенными особенностями, обусловленными её нематериальной сущностью. Далее следует, что данный вид продукта, невозможно продать в физическом смысле, либо уступить другому лицу.

Приобретая билет на определенную постановку или её запись на электронном носителе, потребитель приобретает возможность испытать эмоциональные переживания, вызванные творческой деятельностью исполнителей спектакля, а также возможность удовлетворить свою эстетическую потребность. Однако в данном случае потребитель не обладает возможностью приобрести талант и мастерство исполнителей, непосредственно участвующих в спектакле, а также создателей спектакля. Что не мало важно, приобретая билет на постановку, зритель получает возможность пользоваться благами художественного продукта, лишь на время сценического действия.

Важно отметить, что в процессе потребления театрального продукта участвуют в равной степени как «продавец» - создатель постановки, так и «покупатель» - зритель, потребитель театрального продукта. При этом «продавец» работает для удовлетворения потребностей других, a «покупатель» работает на формирование своего блага и выражает реакцию, необходимую для оценки реализуемого культурного блага. Что в будущем определяет зрительский спрос на данный проект. 


\section{СОВРЕМЕННЫЕ СОЦИАЛЬНО-ЭКОНОМИЧЕСКИЕ ПРОЦЕССЫ: ПРОБЛЕМЫ, ТЕНДЕНЦИИ, ПЕРСПЕКТИВЫ}

Заключительной стадией реализации театрального проекта является определение финансового результата.

Успешная реализация проекта не обуславливается финансовым результатом, как правило продюсер не получает материального вознаграждения и более того сохраняется задолженность перед кредиторами, однако, проект считается успешным, если он состоялся по своим уникальным художественным свойствам, если он обрел успешность у зрителя, если уровень доходов от продажи билетов позволяет покрывать прямые издержки.

Основной фактор оценки проекта - достижение цели по удовлетворению потребностей населения и создания мотивации для производства внутренних благ.

Социокультурная деятельность оказывает значительное влияние на развитие общества и формирование гармонично развитой личности. Наблюдается активное возрастание культурных и духовных потребностей граждан, соответственно модернизируется и процесс предоставления культурных услуг. Традиционные механизмы организации культурной деятельности не всегда отвечают запросам современного потребителя, а также не являются эффективными в реализации задач культурной политики Российской Федерации. Таким образом, возникает необходимость в поиске новых форм организации культурной деятельности.

\section{Примечание}

1 Федеральный закон от 28.06.2014 № 172-Ф3 (ред. От 18.07.2019) «О стратегическом планировании в Российской Федерации».

\section{Список литературы}

1. Акунина Ю.А., Ванина О.В. Инновационные формы молодежного досуга: тренды современности // Культура и образование. 2019. № 2 (33). С. $105-117$.

2. Носкова Н.А., Анализ практик проектного менеджмента в сфере культуры, Петербургский экономический журнал. 2018. № 4. С. 50-56.

3. Городецкая Л.А., Апфельбаум С.М., Мозговой Д.А., Кондрашова К.В. Проект театрального спектакля: экономика, финансирование, договорная 
работа. - М.: Российский институт театрального искусства - ГИТИС, 2020.128 c.]

4. ГОСТ Р 54869-2011. Проектный менеджмент. Требования к управлению проектом. Электронный источник: http://docs.cntd.ru/doc- ument/ 1200089604

5. Гротовский, Е. К бедному театру / Е. Гротовский. - М.: Артист. Режиссер. Театр, 2009. - 298 с. С.13

6. Гузенко О.И., Проектная деятельность как средство капитализации культуры, Молодой исследователь Дона. 2017. № 6 (9). С. 162-172.

7. Дадамян Г. Культурную жизнь страны будут проектировать продюсеры, 2008, 19 декабря. Электронный источник: http://newslab.ru/article/276486

8. Дадамян Г.Г. Борьба двух начал в организации театрального дела в России. Жизнь сцены и контрактный мир: Сборник. М., 1994. 